\title{
The Term "Juvenile Idiopathic Arthritis (JIA)" is Misleading. It Will not be Sufficient to Just Replace this Term
}

\author{
Klaus Rose ${ }^{1}$ D $\cdot$ Oishi Tanjinatus ${ }^{2} \cdot$ Earl B. Ettienne $^{2}$
}

Published online: 16 January 2021

(c) The Author(s), under exclusive licence to Springer Nature Switzerland AG part of Springer Nature 2021

The term "arthritis" describes over 100 rheumatic diseases and conditions and is characterized by pain, stiffness, and inflammation in one or more joints [1]. Rheumatoid arthritis (RA) is the most common chronic arthritis, with the age of onset at approximately $30-50$ years [2].

Historically, arthritic conditions that start at a young age were described by pediatric rheumatologists as "juvenile rheumatoid arthritis" or "juvenile chronic arthritis". The term "juvenile idiopathic arthritis" (JIA) was introduced in 1995 by the International League of Associations for Rheumatology (www.ilar.org). Juvenile idiopathic arthritis is classified by having the onset of chronic joint inflammation prior to the 16th birthday.

Juvenile idiopathic arthritis differentiates patients with inflammation in a few joints (oligoarticular arthritis); many joints (polyarticular arthritis); sub-divides polyarticular arthritis into rheumatoid factor (RF) negative and RF positive; systemic-onset arthritis; inflammation where tendons/ ligaments insert into the bone (enthesitis-related arthritis); psoriatic arthritis; and a seventh category as a catch-all for cases that do not fit into the six other categories [3-6]. Adult-onset Still disease and systemic-onset JIA are the same, as are RF-positive polyarthritis and RF-positive RA; and enthesitis-related arthritis and adult undifferentiated spondyloarthritis [6].

However, there have been challenges with the appropriate use of the term JIA and its predecessors, as these diseases begin prior to the age of 16 years and continue through adulthood. The difference in age of onset of the "JIA" diseases and adult RA is an administrative difference. The literature agrees that the "JIA" diseases do not change

Klaus Rose

klaus.rose@klausrose.net

1 klausrose Consulting, Pediatric Drug Development \& More, Aeussere Baselstrasse 308, 4125 Riehen, Switzerland

2 Howard University College of Pharmacy, Washington, DC, USA in the transition from adolescence to adulthood [3-5, 7-14]. There is already today international scientific agreement that several RA subgroups are identical with JIA subgroups [6]. In our view, the time has come to ask if the term "JIA" is justified at all, or whether it causes more confusion than it is useful. There is now the Boston Massachusetts "Center for Adults with Pediatric Rheumatic Illness" [15]. Its mere nomenclature demonstrates the challenge associated with the designation of age as a differentiator for the diagnosis of an arthritis that is not confined to childhood or adolescence.

Society often gives greater attention to diseases that are more prevalent and have a shorter time to death. For example, when infectious diseases were among the leading causes of death in children, the focus on rare diseases in childhood was limited. When infectious diseases were gradually pushed back because of improvements in environmental conditions, hygiene, and nutrition, interest in noncommunicable diseases such as cancer and inflammatory diseases in young patients increased [16], including the JIA sub-diseases.

In 1968, Shirkey published a concept that children are "therapeutic orphans" [17]. It was taken up by the American Academy of Pediatrics and the US Food and Drug Administration (FDA), resulting in the FDA's separate drug approval in the "pediatric" population, defined as anyone under 17 years of age [18]. The American Academy of Pediatrics demanded "pediatric" studies well before 1997 [19]. Since 1997, the US FDA Modernization Act offers patentprotected drugs an additional 6 months of patent protection ("pediatric exclusivity") for testing them in minors $[18,20]$. In the USA, the US FDA Modernization Act was followed by the Best Pharmaceuticals for Children Act in 2002, the Pediatric Research Equity Act in 2003, and the FDA Safety and Innovation Act in 2012. The FDA Safety and Innovation Act made the pediatric legislation permanent, whereas before it had to be re-authorized every 5 years.

The European Union followed the lead of the USA and demands since 2007 "pediatric investigation plans" (PIPs) as a condition for adult drug approval, defining "children" 
as anybody under 18 years of age [18, 20-22]. However, the age limit of the 17th-18th birthday blurs the difference between the legal and the administrative meanings of the term "child" [20-22].

The US Pediatric Rheumatology Collaborative Study Group (PRCSG, www.prcsg.org) was established in 1973. Eventually, the PRCSG leadership was involved in the training of the leadership of the European Pediatric Rheumatology International Trials Organisation (PRINTO, www.print o.org), founded in 1996 [7]. Representatives from PRCSG and PRINTO emphasize the merit of the "pediatric" studies they performed [7, 23, 24]. PRINTO representatives claim that the pediatric laws, the international research networks, and new efficient drugs improved JIA treatment, in this order [23]. Representatives of the European Medicines Agency (EMA) and PRINTO praise together the European Union Paediatric Regulation [23, 25].

Young patients with arthritis require the extinction of inflammation, thus warranting newer and more effective medications [3]. However, the term "JIA" shows also how the regulatory demand for "pediatric" studies shaped clinical research in a new clinical sub-discipline and even shaped the clinical sub-discipline in its entirety.

US pediatricians can treat patients up to 21 years of age, older with special needs [26], which is a pragmatic administrative rule. However, this does not make every patient seen by a pediatrician physiologically a child. Administrative classifications are necessary in our modern complex society, but we need to overcome the blur of the different meanings of the term "child" that results in studies that lack medical sense and harm by omission where they expose patients to placebo or treatment below the standard of care [21].

For a long time, acetylsalicylic acid was the drug of choice against chronic inflammation because alternative medications were not available $[27,28]$. The PRCSG began studies when new non-steroidal anti-inflammatory drugs (NSAIDs) became available. Its first study compared tolmetin with acetylsalicylic acid [7], leading to the FDA approval of tolmetin in young patients. Additional trials with new NSAIDs followed [29, 30].

Subsequently, methotrexate, which was originally indicated as a chemotherapeutic agent for cancer, was used as a disease-modifying treatment for several autoimmune diseases. It is generally regarded as safe and well tolerated but it has well-known side effects [31, 32]. It is no longer patent protected, production is inexpensive, and therefore costs little.

Unlike cancer where one is threatened with short-term death, inflamed joints result in chronic, painful, and longterm disease. For cancer in minors, effective chemotherapeutics existed as early as the 1960s and 1970s [33-35], allowing pediatric oncologists to save hundreds of thousands of lives. However, effective treatment for inflamed joints and tissue came much later. Treatment improved to some degree with acetylsalicylic acid, NSAIDs, and methotrexate, but a true revolution occurred with the industrial production of modern biologics, including erythropoetin, growth hormone, insulin, monoclonal antibodies (MABs), interleukins (ILs) and IL antagonists, interferons, tumor necrosis factor (TNF) antagonists, small molecules, and more.

The first MAB was FDA approved in 1986 to prevent rejection after kidney transplant. As a mouse antibody, it carried the risk of immune reactions. Thereafter, MABs with much less potential for allergic reactions were developed [36], allowing the treatment of inflammatory diseases to be dramatically improved. A generation ago, young patients with arthritis faced a lifetime of misery, where even the best therapies were barely able to prevent a childhood of pain and disability. Today, their outlook has massively improved [37].

Canakinumab is a human MAB against IL- $1 \beta$. It contrasts to other IL-1 $\beta$ antagonists such as anakinra and rilonacept because it does not require frequent administration [38, 39]. Canakinumab was first developed for RA, but failed. The development team identified diseases characterized by an overproduction of IL-1 $\beta$, including crypoyrin-associated periodic syndrome, systemic-onset JIA, adult-onset Still disease, TNF-receptor-associated periodic syndrome, and familial Mediterranean fever. In these diseases, canakinumab is highly effective [40]. A patient who reports their first fever attacks before his/her 16th birthday is diagnosed with JIA (seventh category), while a first diagnosis after the 16th birthday will leave them diagnosed "only" with crypoyrinassociated periodic syndrome, TNF-receptor-associated periodic syndrome, adult-onset Still disease, or familial Mediterranean fever. Interleukin- $1 \beta$ is the same before and after the $16 \mathrm{th} / 17 \mathrm{th} / 18$ th birthday. There is no valid justification for separate canakinumab efficacy studies before vs after the 16 th/17th/18th birthday.

The FDA and EMA demand "pediatric" studies in patients 2-17 years of age with modern effective MABs, small molecules, and other modern antiinflammatory biologics already approved in adults [20-22]. There are FDAdemanded "pediatric" studies for at least nine effective antiinflammatory biologics, including tocilizumab, tofacitinib, and abatacept; the EMA has so far issued at least 27 PIPs for antiinflammatory biologics [21]. The tofacitinib PIP holds the record among the JIA PIPs with its tenth modification [21, 41]. There are not enough patients worldwide for all FDA/EMA-demanded "pediatric" studies [21, 42]. As a result of the concept of "JIA", young patients are expected to participate in separate "pediatric" studies to advance "pediatric" labels. The flawed children-are-therapeutic-orphans and children-are-not-small-adults concepts that are codified by "pediatric" laws have turned the existence of effective modern JIA drugs into the demand for questionable "pediatric" studies [8, 20-22]. Using administrative age cut-offs 
where there is no corresponding physiological difference is inadvertently creating a bureaucratic hurdle that undermines the accessibility of newer treatment options in minors and compromises the advancement of their healthcare.

The PRCSG had its major merits when it began to focus on young patients with autoimmune arthritis. The fundamentals for today's improved treatment of young patients were not the allegedly "pediatric" studies, but the availability of modern anti-inflammatory drugs and biologics. Where young patients have the same disease as adults, separate "pediatric" efficacy studies may not be necessary. We should re-focus our efforts in healthcare towards the improvement of clinical outcomes also in young patients, rather than regulatory labels.

\section{Declarations}

Funding No funding was received for the preparation of this editorial.

Conflicts of Interest/Competing interest Klaus Rose has worked for 20 years in pharmaceutical companies and has been independent for 10 years, advising on FDA/EMA-requested/demanded pediatric studies. Oishi Tanjinatus and Earl B. Ettienne have no conflicts of interest that are directly relevant to the content of this editorial.

Ethics approval Not applicable.

Consent to participate Not applicable.

Consent for publication Not applicable.

Availability of data and material Not applicable.

Code availability Not applicable.

Authors' contributions This manuscript was drafted by KR and revised by ET and EBE. All authors have approved the final version.

\section{References}

1. Centers for Disease Control and Prevention (CDC). Arthritis in general. 2016. Available from: https://web.archive.org/web/20160 909205959/http://www.cdc.gov/arthritis/basics/general.htm. Accessed 29 Dec 2020

2. Wasserman AM. Diagnosis and management of rheumatoid arthritis. Am Fam Physician. 2011;84(11):1245-52.

3. Nigrovic PA. What adult rheumatologists need to know about juvenile arthritis. 2013. Available from: https://www.the-rheum atologist.org/article/what-adult-rheumatologists-need-to-knowabout-juvenile-arthritis/?singlepage $=1 \&$ theme $=$ print-friendly . Accessed 29 Dec 2020.

4. Nigrovic PA, White PH. Care of the adult with juvenile rheumatoid arthritis. Arthritis Rheum. 2006;55(2):208-16.

5. Nigrovic PA, Raychaudhuri S, Thompson SD. Genetics and the classification of arthritis in adults and children. Arthritis Rheumatol. 2018;70(1):7-17.
6. Martini A, Ravelli A, Avcin T, et al. Toward new classification criteria for juvenile idiopathic arthritis: first steps, Pediatric Rheumatology International Trials Organization International Consensus. J Rheumatol. 2019;46(2):190-7.

7. Brunner HI, Rider LG, Kingsbury DJ, et al. Pediatric Rheumatology Collaborative Study Group: over four decades of pivotal clinical drug research in pediatric rheumatology. Pediatr Rheumatol Online J. 2018;16(1):45.

8. Feger DM, Longson N, Dodanwala H, et al. Comparison of adults with polyarticular juvenile idiopathic arthritis to adults with rheumatoid arthritis: a cross-sectional analysis of clinical features and medication use. J Clin Rheumatol. 2019;25(4):163-70.

9. Oliveira-Ramos F, Eusébio M, Martins FM, et al. Juvenile idiopathic arthritis in adulthood: fulfilment of classification criteria for adult rheumatic diseases, long-term outcomes and predictors of inactive disease, functional status and damage. RMD Open. 2016;2(2):e000304.

10. Packham JC, Hall MA. Long-term follow-up of 246 adults with juvenile idiopathic arthritis: functional outcome. Rheumatology (Oxford). 2002;41(12):1428-35.

11. Bethencourt Baute JJ, Sanchez-Piedra C, Ruiz-Montesinos D, et al. Persistence and adverse events of biological treatment in adult patients with juvenile idiopathic arthritis: results from BIOBADASER. Arthritis Res Ther. 2018;20(1):227.

12. Kearsley-Fleet L, McErlane F, Foster HE, et al. Effectiveness and safety of TNF inhibitors in adults with juvenile idiopathic arthritis. RMD Open. 2016;2(2):e000273.

13. Conti F, Pontikaki I, D’Andrea M. Patients with juvenile idiopathic arthritis become adults: the role of transitional care. Clin Exp Rheumatol. 2018;36(6):1086-94.

14. Burke L, Kirkham J, Arnott J. The transition of adolescents with juvenile idiopathic arthritis or epilepsy from paediatric health-care services to adult health-care services: a scoping review of the literature and a synthesis of the evidence. J Child Health Care. 2018;22(3):332-58.

15. Colón AR. Nurturing childen: a history of pediatrics. Westport: Greenwood Press; 1999.

16. Brigham and Women's Hospital. Pediatric rheumatology for adults. https://www.brighamandwomens.org/medicine/rheumatolo gy-immunology-allergy/services/pediatric-rheumatology-for-adult s. Accessed 29 Dec 2020.

17. Shirkey H. Therapeutic orphans. J Pediatr. 1968;72(1):119-20.

18. Hirschfeld S, Saint-Raymond A. Pediatric regulatory initiatives. Handb Exp Pharmacol. 2011;205:245-68.

19. Guidelines for the ethical conduct of studies to evaluate drugs in pediatric populations. Committee on Drugs, American Academy of Pediatrics, Pediatrics. 1995;95(2):286-94.

20. Rose K. The challenges of pediatric drug development. Curr Ther Res Clin Exp. 2019;90:128-34.

21. Rose K. Considering the patient in pediatric drug development: how good intentions turned into harm. London: Elsevier; 2021. https://www.elsevier.com/books/considering-the-patient-in-pedia tric-drug-development/rose/978-0-12-823888-2. Accessed 29 Dec 2020.

22. Rose K, Neubauer D, Grant-Kels JM. Rational use of medicine in children: the conflict of interests story. Rambam Maimonides Med J. 2019;10(3):e0018. https://doi.org/10.5041/RMMJ.10371.

23. Ruperto N, Vesely R, Saint-Raymond A, for the Paediatric Rheumatology International Trials Organisation (PRINTO), et al. Impact of the European paediatric legislation in paediatric rheumatology: past, present and future. Ann Rheum Dis. 2013;72:1893-6.

24. Ruperto N, Martini A. Current and future perspectives in the management of juvenile idiopathic arthritis. Lancet Child Adolesc Health. 2018;2(5):360-70. 
25. Ruperto N, Eichler I, Herold R, et al. A European Network of Paediatric Research at the European Medicines Agency (EnprEMA). Arch Dis Child. 2012;97(3):185-8.

26. Hardin AP, Hackell JM. Committee on Practice and Ambulatory Medicine. Age limit of pediatrics Pediatrics. 2017;140(3):e20172151.

27. Desborough MJR, Keeling DM. The aspirin story: from willow to wonder drug. Br J Haematol. 2017;177(5):674-83.

28. Levinson JE, Baum J, Brewer E Jr, et al. Comparison of tolmetin sodium and aspirin in the treatment of juvenile rheumatoid arthritis. J Pediatr. 1977;91(5):799-804.

29. Lovell DJ, Ruperto N, Giannini EH, et al. Advances from clinical trials in juvenile idiopathic arthritis. Nat Rev heumatol. 2013;9(9):557-63.

30. Giannini EH, Cawkwell GD. Drug treatment in children with juvenile rheumatoid arthritis: past, present, and future. Pediatr Clin North Am. 1995;42(5):1099-125.

31. Chan ES, Cronstein BN. Mechanisms of action of methotrexate. Bull Hosp Jt Dis. 2013;2013(71 Suppl. 1):S5-8.

32. Friedman B, Cronstein B. Methotrexate mechanism in treatment of rheumatoid arthritis. Jt Bone Spine. 2019;86(3):301-7.

33. Adamson PC. Improving the outcome for children with cancer: development of targeted new agents. CA Cancer J Clin. 2015;65(3):212-20.

34. Pearson HA. History of pediatric hematology oncology. Pediatr Res. 2002;52(6):979-92.
35. Rose K. Pediatric oncology at the crossroads: a call for change. Pharmaceut Med. 2020;34(5):297-300.

36. Liu JK. The history of monoclonal antibody development: progress, remaining challenges and future innovations. Ann Med Surg (Lond). 2014;3(4):113-6.

37. Stoll ML, Cron RQ. Treatment of juvenile idiopathic arthritis: a revolution in care. Pediatr Rheumatol Online J. 2014;12:13.

38. Gram $\mathrm{H}$. The long and winding road in pharmaceutical development of canakinumab from rare genetic autoinflammatory syndromes to myocardial infarction and cancer. Pharmacol Res. 2019. pii: S1043-6618(18)31983-2.

39. Gurung P, Kanneganti TD. Autoinflammatory skin disorders: the inflammasomme in focus. Trends Mol Med. 2016;22(7):545-64.

40. Cudrici C, Deuitch N, Aksentijevich I. Revisiting TNF receptorassociated periodic syndrome (TRAPS): current perspectives. Int J Mol Sci. 2020;21(9):3263.

41. EMA. Tofacitinib PIP EMEA-000576-PIP03-12-M02. 2019. https ://www.ema.europa.eu/en/documents/pip-decision/p/0071/2019ema-decision-22-march-2019-acceptance-modification-agree d-paediatric-investigation-plan_en.pdf. Accessed 29 Dec 2020.

42. Hwang TJ, Tomasi PA, Bourgeois FT. Delays in completion and results reporting of clinical trials under the Paediatric Regulation in the European Union: a cohort study. PLoS Med. 2018;15(3):e1002520. 